\title{
Utero-cutaneous Fistula after Caesarean Section
}

\author{
IPALAM
}

(J Bangladesh Coll Phys Surg 2018; 36: 132-134)

DOI: http://dx.doi.org/10.3329/jbcps.v36i3.37039

Introduction :

Uterocutaneous fistula is the abnormal communication between uterus and skin is a rare occurrence. A fistula is an abnormal communication between two epithelial surfaces of two different organs usually lined by granulation or epithelial tissue ${ }^{1}$.

\section{Objective:}

To share our experience in the management of this rare condition.

\section{Case Report:}

A 21 years-old lady para-1, presented in hospital with cyclical bloody discharge from an opening in lower abdomen $5-6 \mathrm{~cm}$ above the caesarian section scar for last three months. The patient had history of caesarian section due to fetopelvic disproportion 15 months back in a peripheral private clinic. Though her caesarian section wound seems to be apparently healthy, few days after caesarian section she noticed a little swelling just above the caesarian section wound. Then repeated dressing was done with an aim to heal the area spontaneously but failed. Then after consultation with a local doctor excision of that tissue was done in a fashion of secondary suture. However discharge still was coming from the wound. Patient had lactational amenorrhea for 12 months, and then she started menstruation with consequent cyclical bloody discharge from the cutaneous wound. Later she was admitted in SSMC Mitford Hospital. Later sonogram and subsequently hysterosalpingography was done and confirmed the case as uterocutaneous fistula. Later hysterotomy was done and uterocutaneous fistulous tract identified and excised. Uterine wound closed and area of skin at fistula was reconstructed.

Address of Correspondence: Dr. Irin Parveen Alam, , Associate Prof Obstetrics \& Gynae SSMC Mitford Hospital. Mobile- 88-01715348398, E-mail: dririn.alam@yahoo.com

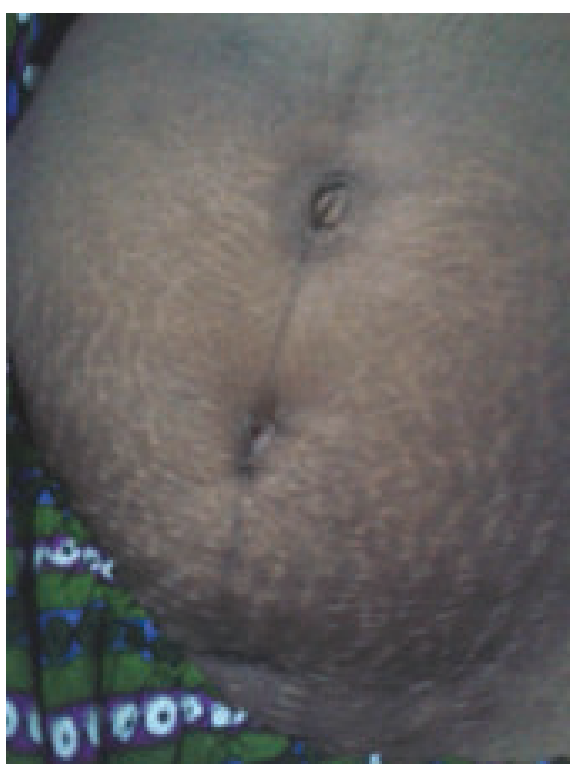

Fig.-1: Fistula below umbilicus

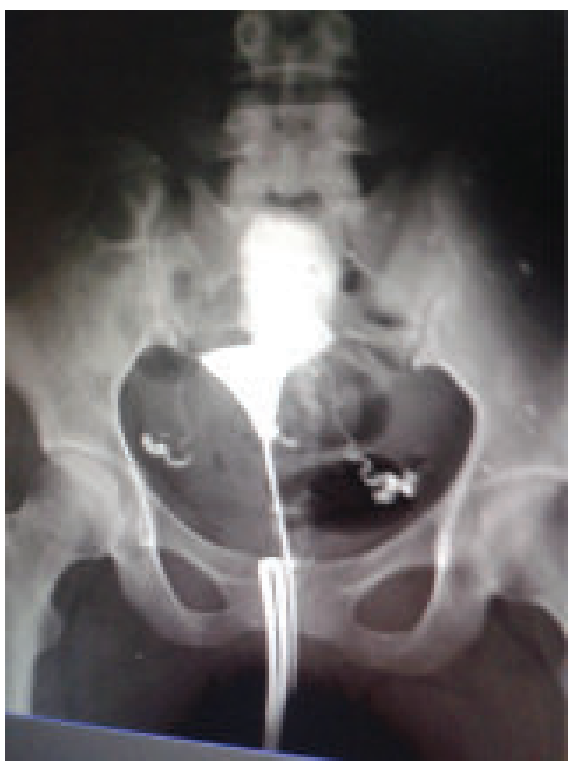

Fig.-2: HSG showing dye outside uterus 


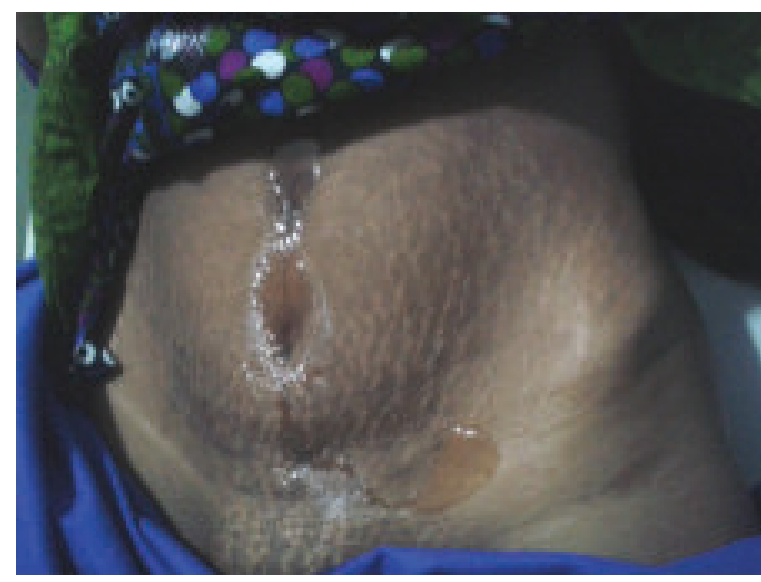

Fig.-3: After $H S G$

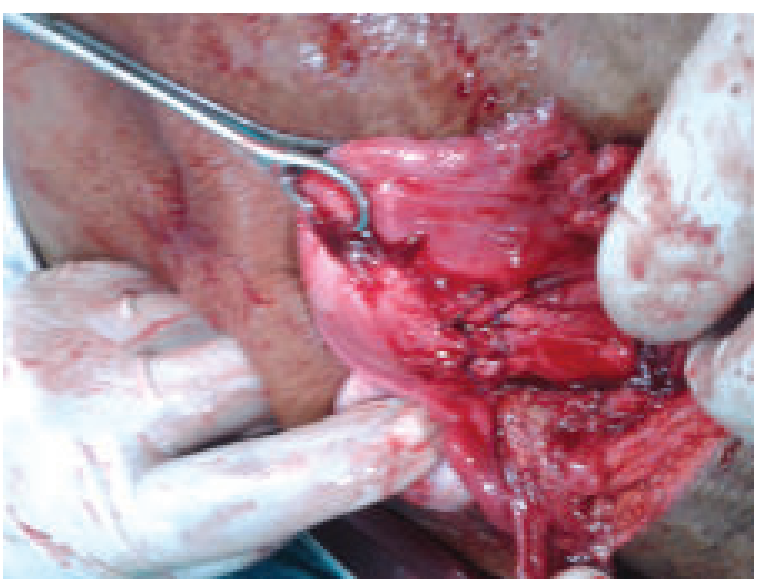

Fig.-5: After closure of uterus

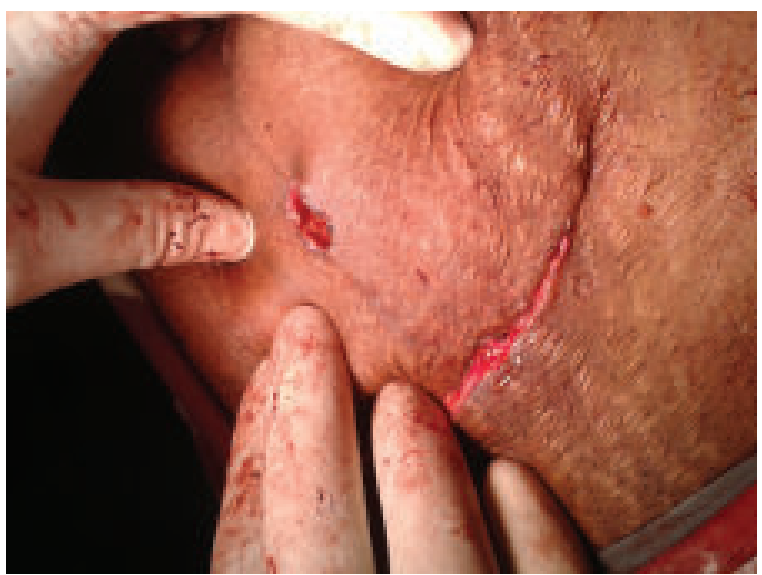

Fig.-7:

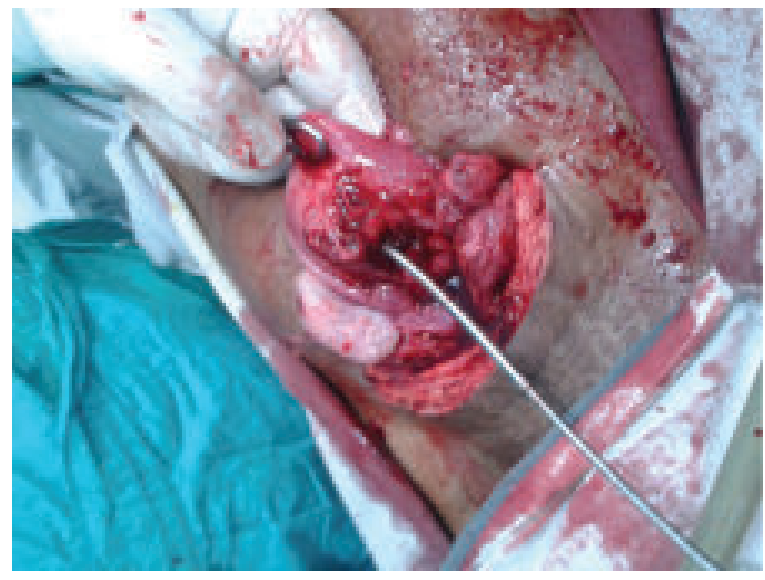

Fig.-4: Opening in Uterus

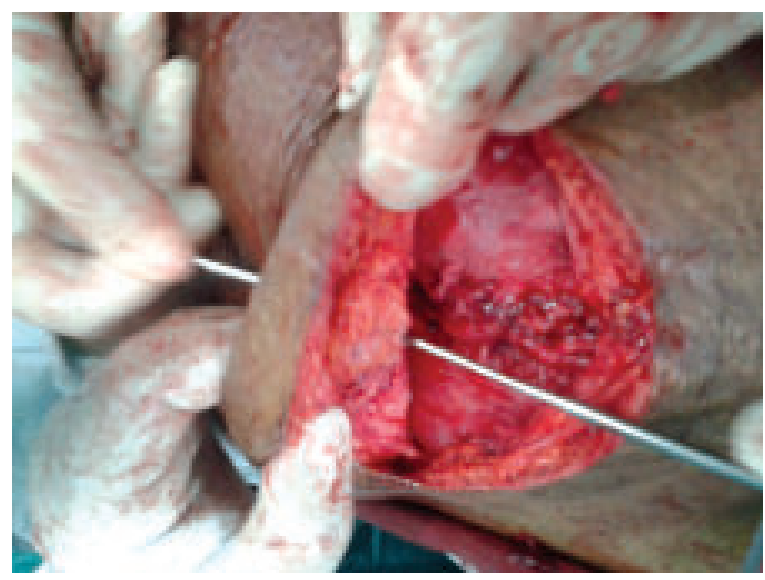

Fig.-6: Fistulous tract with skin

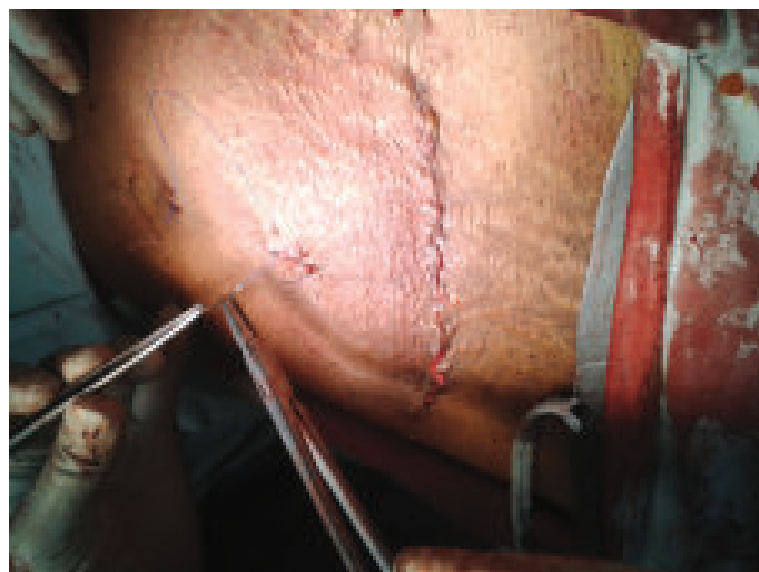

Fig.-8: After reconstruction 


\section{Discussion:}

Uterocutaneous fistula is extremely rare and its aetiology is usually surgery, obstetric, infection or tumour related ${ }^{2}$. Intrauterine infection which subsequently finds its way through uterine scar and adherent adjacent anterior abdominal wall to exterior is the cause of fistulous tract in this case. Diagnosis can be done with a fistulogram, methylen blue injected transcervically, or use of contrast enhanced computed tomography (CT) scan as well as magnetic resonance imaging (MRI) or hysterosalpingography (HSG) ${ }^{3}$.

\section{Results:}

The patient recovered well and was discharged 5 days post-operatively.

\section{Conclusions:}

Uterocutaneous fistula is an exceptional rarity. Once the diagnosis is made, laparotomy and excision of fistulous tract is the operation of choice.

\section{Acknowledgement :}

Prof. A. Z. M. Shakhawat Hossain, Prof. of Surgery, Prof. Ratu Romana Binte Rahman. Prof. of Obst. \& Gynae. Dr. Rashed Ashraf (A/R Dept of Surgery) SSMC Mitford Hospital.

\section{Reference:}

1. Loue V, Koffi A, Adjoby R, N'Guessan K, Alla C, et al. (2013) Postmyomectomy uterocutaneous fistula. J Gynecol Surg 1: 3638.

2. 2. EldemG, Turkbey B, Balas S, Akpinar E (2008) MDCT diagnosis of uterocutaneous fistula. European Journal of Radiology extra 67: e129-e130

3. Shukla D, Pandey S, Pandey LK, Shukla VK (2006) Repair of uterocutaneous fistula. Obstet Gynecol 108: 732-733. 